\title{
Downsizing the target: the underwater closure technique
}
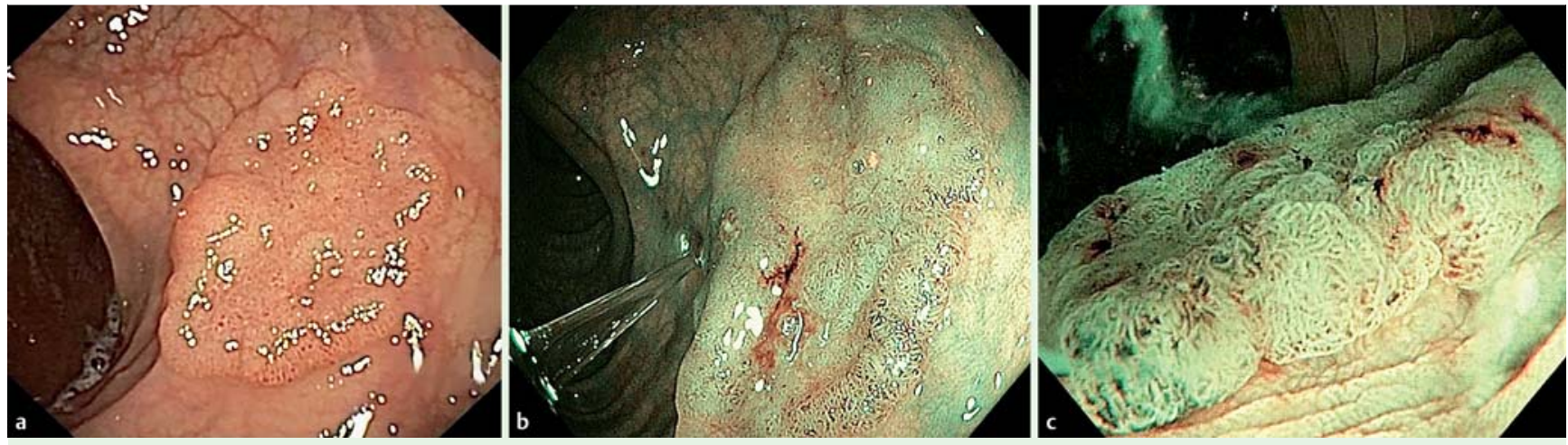

Fig. 1 Endoscopic images showing a laterally spreading tumor in the sigmoid colon of a 77-year-old man as seen: a under high definition white light; $\mathbf{b}$ with narrow band imaging; and $\mathbf{c}$ underwater.
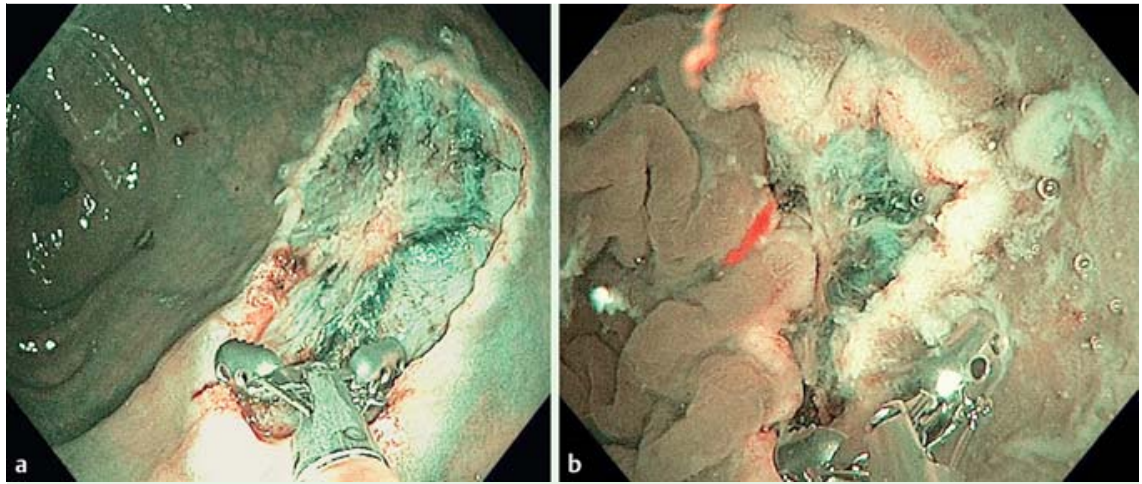

Fig. 2 Endoscopic images of the laterally spreading tumor comparing the resection ulcer size with the help of an opened biopsy forceps $(9 \mathrm{~mm})$ : $\mathbf{a}$ before water infusion; $\mathbf{b}$ after water infusion.
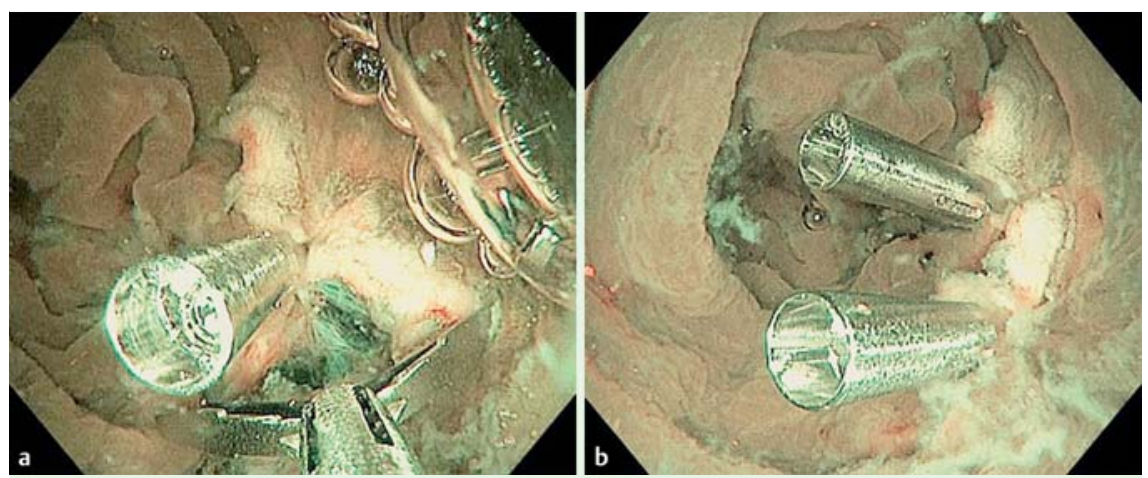

Fig. 3 Endoscopic views of the underwater closure technique.

A 77-year-old man with a 3-cm slightly elevated, nongranular type, laterally spreading tumor (LST-NG 0-IIa) of the sigmoid colon was referred to our institute for endoscopic resection ( $\mathbf{F i g} \mathbf{1}$ ). Piecemeal underwater endoscopic mucosal resection (UEMR) was carried out with a high definition narrow band endoscope (CF-H190L; Olympus Europa SE, Ham- burg, Germany). After UEMR, the margins were ablated using argon plasma coagulation. Histology revealed an adenomatous polyp with high grade dysplasia and free deep resection margins. Because of the patient's need to resume antiplatelet therapy with clopidogrel, prophylactic closure of the resection site was carried out.

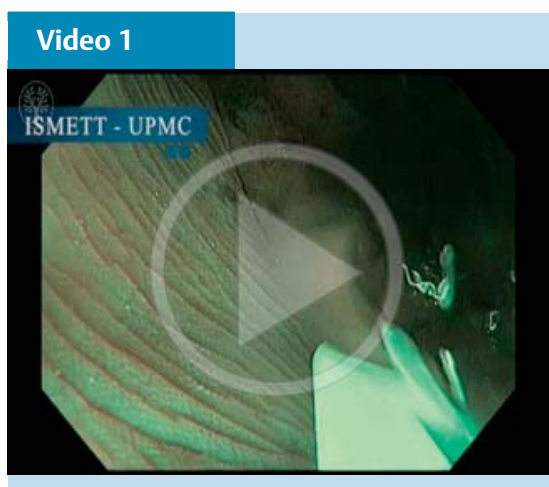

Downsizing the target: the underwater closure technique. After piecemeal underwater endoscopic mucosal resection of a laterally spreading tumor in the sigmoid colon, the size of the resection defect was seen to be reduced following water infusion, and the defect was closed using an underwater technique.

After water infusion, the resection borders "floated," and there was a significant reduction in the size of the resection defect ( Video 1$)$. Opened biopsy forceps (Radial Jaw 4; Boston Scientific Corp, Natick, Massachusetts, USA), which were placed over the post-polypectomy ulcer before and after water infusion, clearly confirmed that there was a reduction in the size of the resection defect ( Fig. 2). In view of the downsizing, the underwater closure technique was applied. By "floating" the mucosa and submucosa away from the deeper muscularis layer [1], underwater closure allowed an easier apposition of the resection borders with complete closure of the resection defect using only two endoclips (Instinct clip; Cook 
Medical, Winston-Salem, North Carolina, USA) ( $\bullet$ Fig.3).

No large prospective randomized trials have assessed clip strategy, so it is unclear how effective a strategy of clip placement would be in preventing post-polypectomy bleeding [2]. The results from a recent retrospective study suggested that colonoscopists might want to consider prophylactic clip closure in cases they consider to be high risk, including those involving larger defects, large defects in the proximal colon, and larger defects in patients requiring re-anticoagulation or the use of antiplatelet agents such as clopidogrel [3].

Although this report does not provide any new information about the value of prophylactic clip closure, it shows how underwater closure may represent a new method of downsizing and "clip-saving." This could help the endoscopist when a defect closure with border apposition is needed.

Endoscopy_UCTN_Code_TTT_1AQ_2AD

Competing interests: None

\section{Gabriele Curcio, Antonino Granata, Dario Ligresti, Mario Traina}

Endoscopy Service, Department of Diagnostic and Therapeutic Services, Mediterranean Institute for Transplantation and Advanced Specialized Therapies

(ISMETT), Palermo, Italy

\section{References}

1 Binmoeller KF, Weilert F, Shah J et al. "Underwater" EMR without submucosal injection for large sessile colorectal polyps (with video). Gastrointest Endosc 2012; 75 : 1086-1091

2 Parikh ND, Zanocco K, Keswani RN et al. A cost-efficacy decision analysis of prophylactic clip placement after endoscopic removal of large polyps. Clin Gastroenterol Hepatol 2013; 11: 1319-1324

3 Liaquat H, Rohn E, Rex DK. Prophylactic clip closure reduced the risk of delayed postpolypectomy hemorrhage: experience in 277 clipped large sessile or flat colorectal lesions and 247 control lesions. Gastrointest Endosc 2013; 77: 401 -417
Bibliography

Dol http://dx.doi.org/

10.1055/s-0034-1392636

Endoscopy 2015; 47: E369-E370

(c) Georg Thieme Verlag KG

Stuttgart · New York

ISSN 0013-726X

\section{Corresponding author}

\section{Gabriele Curcio, MD}

Department of Diagnostic and Therapeutic Services

ISMETT

Via Tricomi 5

90127, Palermo

Italy

Fax: +39-091-2192400

gcurcio@ismett.edu 